\title{
BMJ Open Access to essential medicines for children: a cross-sectional survey measuring medicine prices, availability and affordability in Hanam province, Vietnam
}

\author{
Dai Xuan Dinh (D) , ${ }^{1}$ Huong Thi Thanh Nguyen, ${ }^{1}$ Van Minh Nguyen ${ }^{2}$
}

To cite: Dinh DX, Nguyen HTT, Nguyen VM. Access to essential medicines for children: a crosssectional survey measuring medicine prices, availability and affordability in Hanam province, Vietnam. BMJ Open 2021;11:e051465. doi:10.1136/ bmjopen-2021-051465

- Prepublication history and additional supplemental material for this paper are available online. To view these files, please visit the journal online (http://dx.doi.org/10.1136/ bmjopen-2021-051465).

Received 21 March 2021 Accepted 15 July 2021

D Check for updates

(C) Author(s) (or their employer(s)) 2021. Re-use permitted under CC BY-NC. No commercial re-use. See rights and permissions. Published by BMJ.

${ }^{1}$ Department of Pharmaceutical Management and

PharmacoEconomics, Hanoi University of Pharmacy, Hanoi, Viet Nam

${ }^{2}$ Center for Population Health Sciences, Hanoi University of Public Health, Hanoi, Viet Nam

Correspondence to

Dai Xuan Dinh;

dinhxuandai.224@gmail.com

\section{ABSTRACT}

Objective To identify the availability, prices and affordability of essential medicines for children (cEMs) in Hanam province, Vietnam.

Design Cross-sectional study.

Setting One city and five districts of Hanam province. Participants 66 public health facilities and 66 private drugstores.

Primary and secondary outcome measures The standardised methodology of the WHO and Health Action International was used to investigate 30 paediatric essential medicines. For each medicine, data were collected for two products: the lowest-priced medicine (LPM) and the highest-priced medicine (HPM). The availability of medicine was computed as the percentage of facilities in which this medicine was found on the day of data collection. Median prices of individual medicines were reported in local currency. Affordability was calculated as the number of days' wages required for the lowestpaid unskilled government worker to purchase standard treatments for common diseases. Data were analysed using R software V.4.1.0.

Results The mean availability of LPMs in the private sector $(33.2 \%, \mathrm{SD}=38.0 \%)$ was higher than that in the public sector $(24.9 \%, S D=39.4 \%)(p<0.05)$. The mean availability of HPMs was extremely low in both sectors (11.3\% and $5.8 \%$, respectively). The mean availability of cEMs in urban areas was significantly higher than that in rural areas $(36.5 \%$ and $31.6 \%$, respectively, $p<0.05)$. In the public sector, the prices of LPMs were nearly equal to the international reference prices (IRPs). In the private sector, LPMs were generally sold at 4.06 times their IRPs. However, in both sectors, the affordability of LPMs was reasonable for most conditions as standard treatments only cost a day's wage or less.

Conclusion The low availability was the main reason hindering access to cEMs in Hanam, especially in the countryside. A national study on cEMs should be conducted, and some practical policies should be promulgated to enhance access to cEMs.

\section{BACKGROUND}

In 2019, approximately 5.2 million children under 5 years (2.4 million newborns) and
Strengths and limitations of this study

- This research followed the reliable and standardised methodology developed by WHO/Health Action International.

- International reference prices of Management Sciences for Health were used to calculate median price ratios for medicines, allowing for international comparison among countries. However, these reference prices are old (from the year 2015).

- The availability of medicines was computed for the day of data collection, not for the whole month/year.

- Only 30 surveyed medicines cannot reflect the whole medicines for children on the market.

- This study was conducted in one province, and therefore, the results may not be truly representative of Vietnam. A national survey should be conducted, and factors involving the low availability of essential medicines for children should be comprehensively analysed.

500000 children under 5-9 years died all over the world. ${ }^{1}$ There were an estimated 7.4 million under 5 children in Vietnam, with an under 5 mortality rate of 21.0 per 1000 live births in 2019. ${ }^{23}$ Infectious diseases, such as pneumonia and diarrhoea, along with preterm birth complications, birth asphyxia/ trauma and congenital anomalies, are globally leading causes of death in children under 5 years of age. These diseases can be prevented or treated through simple and affordable interventions, such as adequate nutrition, immunisation, safe drinking water and appropriate treatment of common childhood illnesses. ${ }^{14}$

Essential medicines (EMs) are those that satisfy the priority healthcare need of the population; selected with due regard to public health relevance, evidence on safety, efficacy and comparative cost-effectiveness. ${ }^{5}$ However, nearly two billion people have 
no access to EMs. ${ }^{6}$ For children, EMs play a key role in improving health and saving lives. In order to enhance access to child-appropriate medicines, WHO launched the campaigns named 'Make Medicines Child Size' in 2007 and 'Better Medicines for Children Project' in 2009. ${ }^{7}$ Furthermore, the first WHO Model List of Essential Medicines for Children (WHO EMLc) was published in 2007 and updated every 2 years. To create a standard methodology for measuring medicine prices, availability, affordability and price components, WHO in collaboration with Health Action International (HAI) published the first guideline in 2003 and the second edition in 2008. ${ }^{8}$ Hitherto, there has been a multitude of studies using these guidelines in different countries. However, most of previous studies focused on EMs for adults. There are only few studies on EMs for children (cEMs). ${ }^{9-21}$ Their results showed that low availability, high prices and poor affordability have kept cEMs out of reach.

In Vietnam, the healthcare system consists of the public sector and the private sector. In 2017, there were 13583 public health facilities, including 1085 hospitals and 11 830 primary healthcare centres across the country. ${ }^{22}$ In 2020, there were roughly 61000 licensed private drugstores, including $21000 \mathrm{NT}$ (Nha Thuoc) drugstores and 40000 QT (Quay Thuoc) drugstores. According to the Vietnamese Pharmacy Law, NTs are drugstores located in urban areas, opened by university pharmacists and having the right to prepare medicines according to prescriptions. University pharmacists have the right to substitute one drug with another having the same active ingredients, preparation form and dose when buyers so agree. QT drugstores are normally smaller than NT drugstores in scale, located in rural areas and not having the right to prepare medicines according to prescriptions. Both college pharmacists and university pharmacists can be the owners of QT drugstores.

In Vietnam, the first national essential medicines list (NEML) was released in 1985. Up to now, the seventh NEML has been published. ${ }^{23}$ This list consists of 510 chemical medicines, 357 traditional medicines and 380 herbal medicines used for both adults and children. There is no separate list of cEMs in Vietnam. Several previous surveys were conducted to investigate the availability, prices and affordability of EMs for adults. Up to now, there has been only one small-scale study (with 14 public health facilities and 26 private drugstores) on cEMs conducted in Bacninh in $2014^{21}$ The study results showed that in this province, the availability of cEMs was low in both sectors, and the prices of lowest-priced medicine (LPMs) were acceptable. However, the affordability of cEMs was not reported. ${ }^{21}$ Our study aimed to survey the availability, prices and affordability of cEMs in Hanam, a northern province of Vietnam with an area of $861.9 \mathrm{~km}^{2}$ and about 854500 inhabitants.

\section{METHODS}

This survey followed the WHO/HAI standardised methodology on measuring medicine prices, availability and affordability. ${ }^{78} \mathrm{~A}$ data collection form was developed based on the WHO/HAI methodology, and used to collect information on medicine availability and prices in Hanam from October to December 2020. This province was chosen for research by following rationales. First, Hanam is contiguous to Hanoi, the capital of Vietnam. The adjacency between the two areas facilitated the process of data collection in the context of the outbreak of the COVID-19 pandemic. In addition, during 2020, the three biggest cities of Vietnam (Hanoi, Danang and Hochiminh city) were significantly influenced by this pandemic. Numerous patients with COVID-19 were continuously discovered. Social distancing was applied two times in April and July 2020. Besides the paucity of human resources and funds, the above-mentioned difficulties contributed to hindering our capability to conduct a national survey. During the data collection interval, Hanam was devoid of patients with COVID-19, and social distancing was not applied in this province.

An official letter of endorsement from the Hanam Department of Health was sent to surveyed facilities to facilitate data collection. All interviewees (pharmacists working in public health facilities and private drugstores) were informed about the study's objectives and methodology. Verbal informed consent was obtained from all of them. The identity of facilities and pharmacists was kept confidential.

\section{Patient and public involvement}

No patient involved.

\section{Surveyed areas and health facilities}

Data were collected in six areas, including Phủ Lý city (major urban centre) and five districts reachable within 1-day travel from Phủ Lý city using motorbikes (Duy Tiên, Thanh Liêm, Lý Nhân, Kim Bảng and Bình Lục). Each area included the requisite number of health facilities and covered a population of about 100000 inhabitants or more. In each area, one main public hospital and ten primary healthcare centres were randomly selected for the public sector group. For each public facility, a licensed private drugstore closest to it was selected for the private sector group. All facilities were within 3 hours travel from the main public hospital. A total of 66 public health facilities and 66 private drugstores were selected for investigation.

\section{Surveyed medicines}

Thirty medicines selected for investigation were divided into two lists (table 1). The core list consisted of 14 medicines opted from the list of 23 core medicines in the WHO's guidance 'Better Medicines for Children Project'. ${ }^{7}$ Nine other medicines from WHO's core list not registered in Vietnam were removed and superseded by nine supplementary medicines (similar active ingredients 


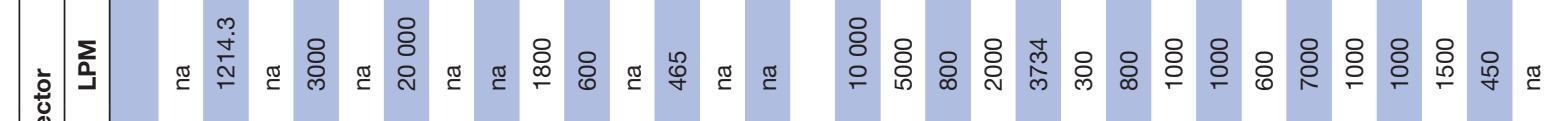

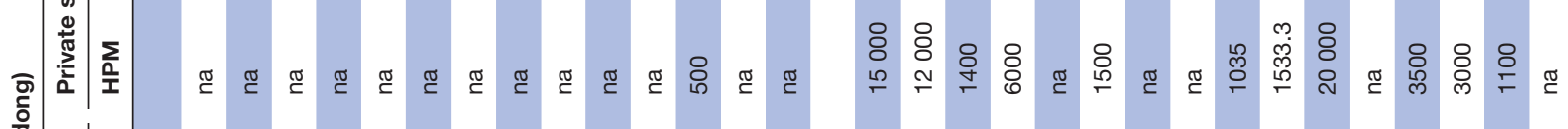

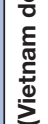

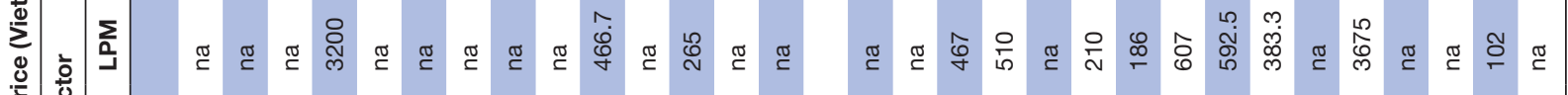

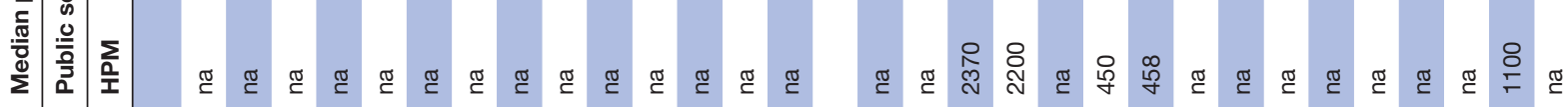

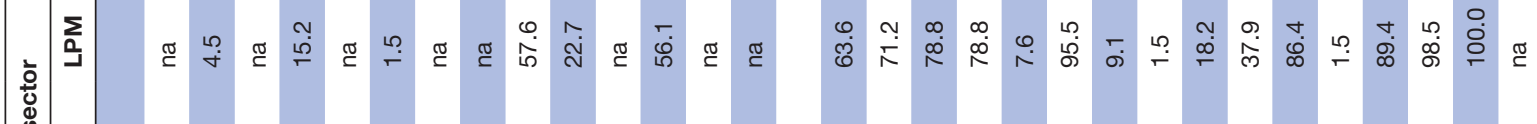

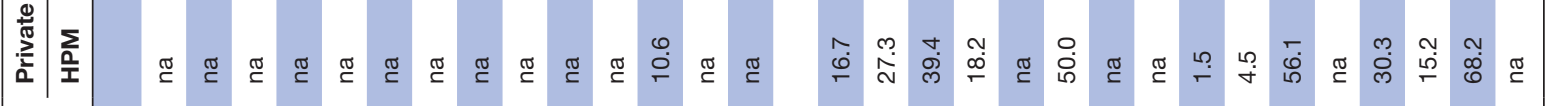

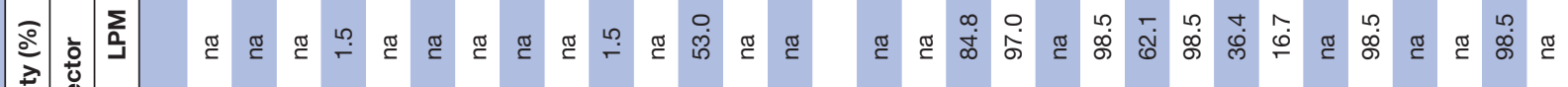
¿)

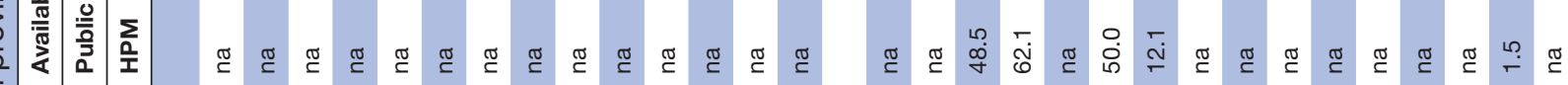
จุ

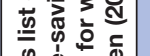

을 过

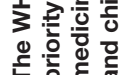

节

$\overline{\widetilde{m}} \stackrel{\bar{\sigma}}{=}$

ट

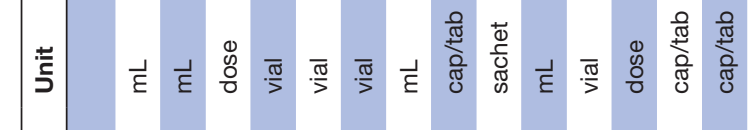

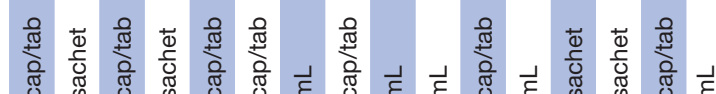

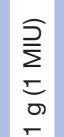

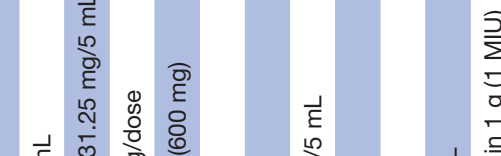

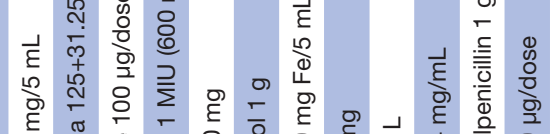

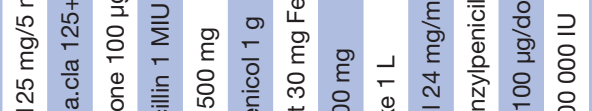

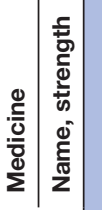

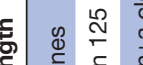

$\frac{1}{\varepsilon}$

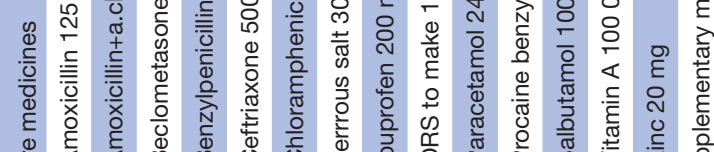

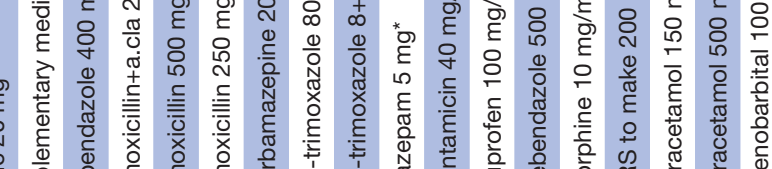

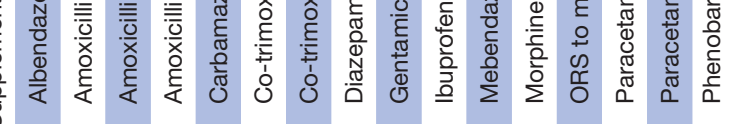

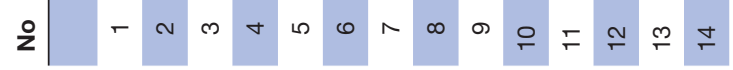

$\stackrel{\circ}{\circ} \leftarrow \stackrel{\infty}{\leftarrow} \circ \stackrel{\sim}{\sim} \approx$

ก กั

g) $\stackrel{*}{\varepsilon}$

$\underset{c}{\infty}$

융

$\frac{\bar{c}}{\frac{\bar{c}}{5}}$

$\stackrel{8}{\circ}$

음

$\overrightarrow{\vec{\omega}}$

음.

N

i

㕝

○

?

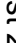


but alternate dosage forms and/or strengths). Seven other supplementary medicines were chosen to treat important national health problems and the burden of local diseases for children (such as pneumonia, diarrhoea, colds and pain). When developing the supplementary list, we referenced medicine lists from previous studies, ${ }^{9-20}$ guidelines and documents (such as the NEML (2018), ${ }^{23}$ the seventh WHO EMLc (2019), ${ }^{24}$ the WHO's list of priority life-saving medicines for women and children $(2012)^{25}$. The suitability of selected medicines was also checked through the results from a pilot test in a public health facility and a private drugstore in October 2020. The selection of surveyed medicines was described in detail in online supplemental file.

\section{Data collection}

After receiving standardised training, data collectors paid a visit to selected facilities in pairs and checked the availability and prices of the selected medicines. For each medicine, data were collected for two products: the LPM and the highest-priced medicine (HPM) (following the WHO's instructions in the Better Medicines for Children Project ${ }^{7}$ ). Medicines were physically seen to confirm their availability. Medicine prices were recorded from product labels or computers. Before leaving each facility, data collectors checked data collection forms to guarantee that they were complete, accurate and legible.

\section{Data analysis}

Collected data were entered into the computerised WHO/HAI Workbook. To ensure data quality and the accuracy of results, data were entered twice by two people independently and checked through available functions of the Workbook (double entry and data checker).

\section{Availability}

The availability of medicine was computed as the percentage of facilities in which this medicine was found on the day of data collection. The normality of data was checked using histogram, Q-Q plot, boxplot, Anderson-Darling test and Shapiro-Wilk test $(p>0.05$ indicating a normally distributed continuous variable). The mean availability of cEMs between urban areas (NT drugstores) and rural areas (QT drugstores) was compared using the Wilcoxon rank-sum test. Differences in medicine availability among six areas (city/district) were analysed using the Kruskal-Wallis rank-sum test, and the Dunn test for multiple comparisons in R software V.4.1.0.

\section{Medicine price}

Median supplier prices from the International Medical Products Price Guide of Management Sciences for Health $(\mathrm{MSH})^{26}$ were usually used to calculate median price ratio (MPR), thereby facilitating regional and international comparisons. At present, these prices are quite old because the most recent medicine prices of MSH are for the year 2015. Therefore, median prices of individual medicines were reported in local currency as per the WHO/HAI's instructions. ${ }^{27}$ The medicine prices were adjusted for inflation and price changes. US\$1 in 2015 is equivalent in purchasing power to roughly US $\$ 1.09$ in 2020 , an increase of US $\$ 0.09$ over 5 years. ${ }^{28}$

Median Price Ratio $(M P R)=\frac{\text { Median local unit price }}{\text { International reference unit price }}$

\section{Affordability}

Affordability was estimated using the daily wage of the lowest-paid unskilled government worker ( $₫ 102333.3333$ / day). ${ }^{29}$ The treatment duration of a medicine is the number of days for a typical course of therapy. The treatment duration for an acute illness and a chronic disease is the total duration of therapy and 30 days, respectively. ${ }^{8}$ The treatment schedule was taken from British National Formulary for children 2019-2020 ${ }^{30}$ and the guidance on diagnosis and treatment for children common diseases published by the Vietnam Ministry of Health in 2015 (QĐ3312/QĐ-BYT (Quyết Định-Bộ Y Tế)). ${ }^{31}$

\section{RESULTS \\ The availability and prices of cEMs on the day of data collection}

The availability of core medicines was extremely low. There was only one core medicine whose availability was higher than $50 \%$ in both sectors (salbutamol). For supplementary medicines, the availability of amoxicillin (250 $\mathrm{mg}$ and $500 \mathrm{mg})$, co-trimoxazole $(80+400 \mathrm{mg})$ and paracetamol $(500 \mathrm{mg})$ was high. Diazepam $5 \mathrm{mg}$, morphine $10 \mathrm{mg} / \mathrm{mL}$ and co-trimoxazole $8+40 \mathrm{mg} / \mathrm{mL}$ were three medicines whose availability in the public sector was far higher than that in the private sector. By contrast, the availability of albendazole $400 \mathrm{mg}$, mebendazole $500 \mathrm{mg}$, oral rehydration salts/solution (ORS) (for $200 \mathrm{~mL}$ ) and paracetamol $150 \mathrm{mg}$ in the private sector was higher than that in the public sector (table 1).

Regarding medicine prices, the LPM prices in the public sector were nearly equal to their international reference prices (IRPs) (IQR: 0.61-1.54). In the private sector, LPMs were generally sold at 4.06 times their IRPs (IQR: 1.06-6.61). For medicines found in both sectors, the prices of LPMs in the private sector were $118.0 \%$ higher than that in the public sector. Overall, the prices of medicines in the private sector were higher than those in the public sector, excluding benzylpenicillin and morphine. There were some LPMs whose unit prices were higher than $2015 \mathrm{MSH}$ prices, including co-trimoxazole suspension $\quad(\mathrm{MPR}=1.54)$, diazepam $\quad(\mathrm{MPR}=2.51)$ and ibuprofen suspension $(\mathrm{MPR}=2.98)$ in the public sector; albendazole $\quad(\mathrm{MPR}=18.13)$, mebendazole $(\mathrm{MPR}=9.11)$, carbamazepine (MPR=8.02), co-trimoxazole suspension $\quad(\mathrm{MPR}=6.61)$, ibuprofen suspension $\quad(\mathrm{MPR}=4.67)$, 
Table 2 Mean availability of paediatric essential medicines

\begin{tabular}{|c|c|c|c|c|}
\hline \multirow{2}{*}{$\begin{array}{l}\text { Mean availability } \\
\text { (SD) }\end{array}$} & \multicolumn{2}{|c|}{$\begin{array}{l}\text { Public sector } \\
\text { ( } \mathrm{n}=66 \text { public health facilities) }\end{array}$} & \multicolumn{2}{|c|}{$\begin{array}{l}\text { Private sector } \\
\text { ( } \mathrm{n}=66 \text { private drugstores) }\end{array}$} \\
\hline & HPM & LPM & HPM & LPM \\
\hline Of 22 NEML medicines & $7.9 \%(18.9 \%)$ & $33.1 \%(43.2 \%)$ & $13.9 \%(21.2 \%)$ & $39.0 \%(40.4 \%)$ \\
\hline Of 14 core medicines & $0.0 \%(0.0 \%)$ & $4.0 \%(14.1 \%)$ & $0.8 \%(2.8 \%)$ & $11.3 \%(20.5 \%)$ \\
\hline
\end{tabular}

HPM, highest-priced medicine; LPM, lowest-priced medicine; NEML, national essential medicines list.

paracetamol suspension $(\mathrm{MPR}=4.58)$ and paracetamol tablet $500 \mathrm{mg}(\mathrm{MPR}=4.06)$ in the private sector (table 1$)$.

The mean availability of cEMs was low in both sectors. The mean availability of all 30 medicines in the private drugstores $(33.2 \%)$ was significantly higher than that in the public facilities $(24.9 \%)(\mathrm{p}<0.05$, Wilcoxon rank-sum test). When the analysis was limited to survey medicines listed on the NEML, their mean availability slightly increased. Furthermore, the mean availability of 14 core medicines was extremely low (table 2).

In the private sector, the mean availability of LPMs in Phủ Lý city, Duy Tiên, Thanh Liêm, Bình Lục, Lý Nhân and Kim Bảng was 41.8\%, 34.2\%, 32.4\%, 29.7\%, 32.4\% and $28.5 \%$, respectively ( $\mathrm{p}=0.0057$, Kruskal-Wallis test). The mean availability of medicines in Phủ Lý city was significantly higher than that in Bình Lục, Kim Bảng and Lý Nhân ( $\mathrm{p}<0.05$, Dunn test) (figure 1$)$. In addition, the mean availability of LPMs in NT drugstores $(36.51 \%$, $\mathrm{SD}=11.03 \%$ ) was significantly higher than that in QT drugstores $(31.63 \%, \mathrm{SD}=6.06 \%) \quad(\mathrm{p}=0.029$, Wilcoxon rank-sum test) (figure 2).

The mean availability of lowest-priced medicines in six areas (private sector)

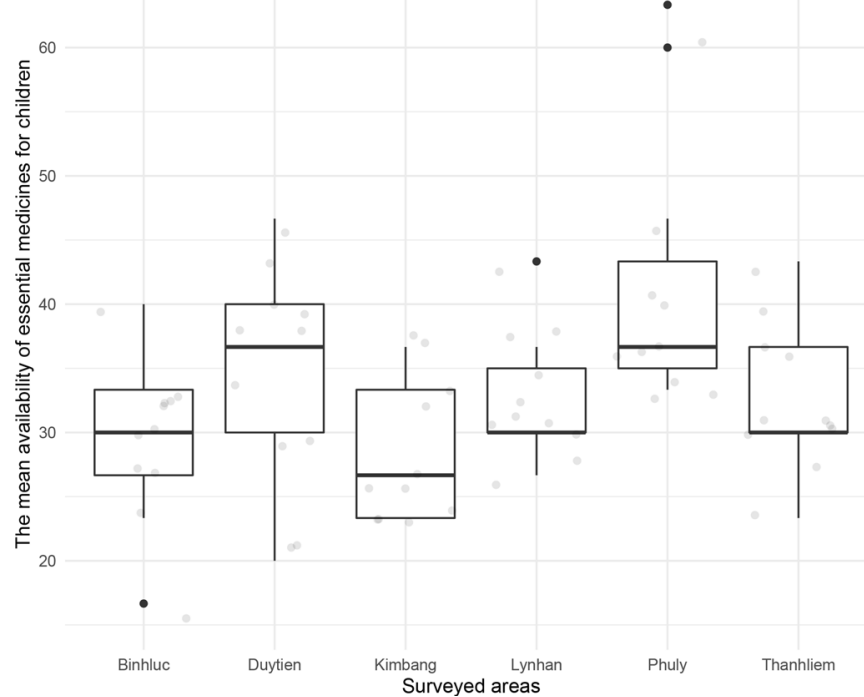

Figure 1 Regional analysis for the private sector: comparison of the mean availability of LPMs in six areas. LPM, lowest-priced medicine.

\section{The affordability of cEMs}

The affordability of LPMs was reasonable for most conditions in both sectors. Almost all standard treatments cost only a days' wage or less. In the private sector, treatments costing over a days' wage of the lowest-paid government worker include tablet carbamazepine $200 \mathrm{mg}$ (1.53 days), powder packet amoxicillin+acid clavulanic $250+31.25$ $\mathrm{mg}$ ( 1.4 days) and suspension co-trimoxazole $8+40 \mathrm{mg}$ / $\mathrm{mL}$ (1.09 days). For HPMs, the standard treatments of powder packet amoxicillin $250 \mathrm{mg}$, powder packet amoxicillin+acid clavulanic $250+31.25 \mathrm{mg}$ and suspension ibuprofen $100 \mathrm{mg} / 5 \mathrm{~mL}$ cost over a days' wage (table 3 ).

\section{DISCUSSION}

This is the first study on cEMs conducted in Hanam province, Vietnam. The results revealed that the mean availability of cEMs was low in both public and private sectors. The prices of child-friendly medicines were high in private drugstores. However, in both sectors, the affordability of cEMs was reasonable for most conditions. The

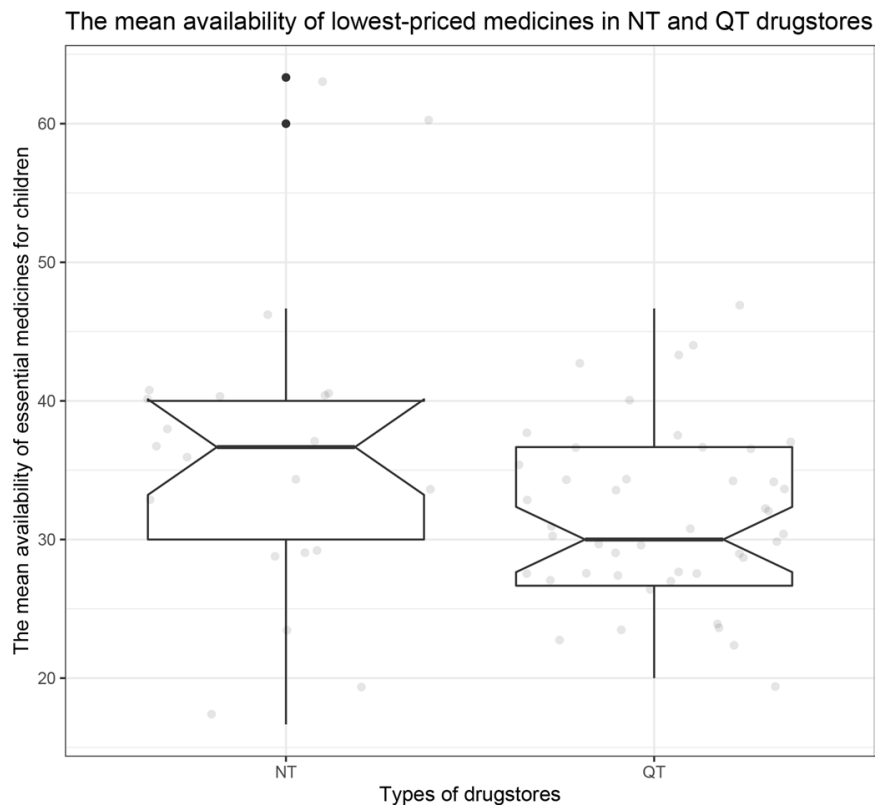

Figure 2 Comparison of the mean availability of LPMs between NT drugstores and QT drugstores. LPM, lowestpriced medicine; NT, Nha Thuoc; QT, Quay Thuoc 
Table 3 Number of days' wages of the lowest-paid government worker needed to purchase standard treatments

\begin{tabular}{|c|c|c|c|c|c|c|}
\hline \multirow[b]{2}{*}{ Condition } & \multirow[b]{2}{*}{ Medicines } & \multirow[b]{2}{*}{ Treatment schedule } & \multicolumn{2}{|c|}{ Public sector } & \multicolumn{2}{|c|}{ Private sector } \\
\hline & & & HPM & LPM & HPM & LPM \\
\hline Asthma & Salbutamol $100 \mu \mathrm{g} /$ dose (inhaler) & One inhaler of 200 doses & na & 0.52 & 0.98 & 0.91 \\
\hline Worm infections & Mebendazole 500 mg (cap/tab) & One single dose & na & na & 0.20 & 0.07 \\
\hline \multirow{3}{*}{$\begin{array}{l}\text { Susceptible infection } \\
\text { including urinary } \\
\text { tract infection, otitis } \\
\text { media, sinusitis, } \\
\text { pneumonia }\end{array}$} & Amoxicillin 250 mg (powder packet) & $\begin{array}{l}\text { Child } 5-11 \text { years: } 500 \mathrm{mg} \text { three } \\
\text { times a day } \times 5 \text { days }=30 \text { sachets }\end{array}$ & 0.64 & 0.15 & 1.76 & 0.58 \\
\hline & $\begin{array}{l}\text { Amoxicillin+acid clavulanic } \\
125+31.25 \mathrm{mg} / 5 \mathrm{~mL} \text { (suspension) }\end{array}$ & $\begin{array}{l}80 \mathrm{mg} / \mathrm{kg} / 24 \text { hours } \times 18.25 \mathrm{~kg} \times 5 \\
\text { days }=7300 \mathrm{mg}(58.4 \mathrm{~mL})\end{array}$ & na & na & na & 0.69 \\
\hline & $\begin{array}{l}\text { Amoxicillin+acid clavulanic } \\
250+31.25 \text { mg (powder packet) }\end{array}$ & $\begin{array}{l}80 \mathrm{mg} / \mathrm{kg} / 24 \text { hours } \times 18.25 \mathrm{~kg} \times 5 \\
\text { days }=7300 \mathrm{mg} \text { ( } 30 \text { sachets })\end{array}$ & na & na & 3.5 & 1.4 \\
\hline Seizure disorder & Carbamazepine 200 mg (cap/tab) & $\begin{array}{l}\text { Child } 1 \text { month to } 11 \text { years: } \\
\text { (maintenance treatment): } 5 \mathrm{mg} / \mathrm{kg} \\
\times 18.25 \mathrm{~kg} \times 3 \times 30 \text { days }=8212.5 \\
\mathrm{mg}(42 \text { tablets) }\end{array}$ & na & na & na & 1.53 \\
\hline \multirow[t]{2}{*}{ Dehydration } & $\begin{array}{l}\text { ORS to make } 200 \mathrm{~mL} \text { (powder } \\
\text { packet) }\end{array}$ & $\begin{array}{l}\text { Moderate dehydration: } \\
75 \mathrm{~mL} / \mathrm{kg} \times 18.25 \mathrm{~kg}=1368.75 \mathrm{~mL} \\
\text { (seven sachets) }\end{array}$ & na & na & 0.24 & 0.07 \\
\hline & ORS to make $1 \mathrm{~L}$ (powder packet) & $\begin{array}{l}\text { Moderate dehydration: } \\
75 \mathrm{~mL} / \mathrm{kg} \times 18.25 \mathrm{~kg}=1368.75 \mathrm{~mL} \\
\text { (two sachets) }\end{array}$ & na & na & na & 0.04 \\
\hline
\end{tabular}

As per $\mathrm{WHO},{ }^{40}$ the median weight for a 5 -year-old boy is $18.3 \mathrm{~kg}$ and that for a 5 -year-old girl is $18.2 \mathrm{~kg}$. The total dosage in table 3 was estimated for a child weighing $18.25 \mathrm{~kg}$.

HPM, highest-priced medicine; LPM, lowest-priced medicine; na, Not available; ORS, oral rehydration salts/solution.

low availability was the main reason hindering access to cEMs in Hanam. The mean availability of cEMs in Hanam was lower than that in Ethiopia (2015), ${ }^{13}$ and Mongolia $(2016)^{15}$; in line with findings in Odisha $(2010-2011)^{12}$; Shaanxi, China $(2012)^{10}$; Armenia $(2013)^{11}$; Bacninh, Vietnam ${ }^{2121}$ and Jiangsu, China (2017). ${ }^{16}$ The extremely low availability of HPMs implied that people did not have many choices when purchasing medicines.

The WHO's list of priority life-saving medicines for children under 5 years old was developed to help countries to select and make available medicines that will have considerable impact on reducing newborn and child morbidity and mortality. However, in Hanam, four medicines featuring on this list (including ceftriaxone, procaine benzylpenicillin, vitamin A and zinc) were unavailable in both sectors. The availability of ORS, paracetamol and amoxicillin was high, which was comparable to the results of Jimma Zone, Ethiopia in 2018. However, in this country, the availability of vitamin $\mathrm{A}$ and zinc was high. ${ }^{20}$ In Vietnam, annually, children aged 6-60 months can get vitamin A free of charge in public health facilities on the first 2 days of June and December (a national campaign). This is one reason explaining why the availability of this vitamin was low in the public sector. In private drugstores, some common formulations of vitamin A include vitamin A $5000 \mathrm{IU}$ and vitamin A-D. For zinc, tablets $10 \mathrm{mg}$ or $70 \mathrm{mg}$, and liquid formulations for children are popular. However, those formulations are not on the WHO EMLc (seventh, 2019). ${ }^{24}$

In the public sector, the availability of morphine and diazepam was far higher than that in the private sector. The availability of these two medicines was extremely low in the private 
sector, similar to the results of Shaanxi, China $(2012)^{10}$; Iran $(2014)^{32}$ and Zhejiang, China (2018). ${ }^{33}$ Besides, phenobarbital was unavailable in both sectors, which is in line with the result of Mongolia (2016).$^{15}$ The rationale for these results is that narcotic and psychotropic medicines are restricted in use in Vietnam, and only few drugstores with special permission are eligible to sell these medicines. In addition, the government annually conducts deworming campaigns for children. Therefore, anthelmintics (such as albendazole and mebendazole) were unavailable in the public sector. In Malawi (2017), these medicines were also unavailable in public health facilities. ${ }^{34}$ In Hanam, inhabitants can easily purchase albendazole and mebendazole in private drugstores. Although their prices were extremely high in comparison with the IRPs, people still can afford them because treating worm infections cost only less than one-fifth day's wage.

Respiratory infections (pneumonia) and diarrhoea are common diseases among Vietnamese children. ${ }^{35-37}$ Antibiotics are commonly used to treat infections but their availability was extremely low, except for sachets/tablets amoxicillin and co-trimoxazole. In Vietnam, these two antibacterials were popularly sold in drugstores due to their low prices. One of the paediatric-appropriate dosage forms is oral suspension. In Jordan and Rwanda, the availability of this formulation was high (for paracetamol and co-trimoxazole). ${ }^{38}{ }^{39}$ Conversely, in Hanam, the availability of this dosage form was low (for amoxicillin, paracetamol, ibuprofen and co-trimoxazole). People tend to use powder packets instead of suspensions and solution bottles. The high prices of suspensions can be the first reason. In addition, each powder packet is a single dose, used for one time. The convenience and easiness in use and preservation are other rationales for the high availability of powder packets in Hanam. Except for co-trimoxazole, five other suspensions do not feature on the 2018 NEML nor the 2012 WHO's list of priority life-saving medicines for women and children. Amoxicillin $125 \mathrm{mg} / 5 \mathrm{~mL}$, amoxicillin+acid clavulanic $125+31.25 \mathrm{mg} / 5 \mathrm{~mL}$ and ferrous salt $30 \mathrm{mg} \mathrm{Fe} / 5 \mathrm{~mL}$ (three WHO's core medicines) were unavailable in all 132 surveyed facilities. The availability of paracetamol $24 \mathrm{mg} / \mathrm{mL}$ (a WHO's core medicine) and ibuprofen $100 \mathrm{mg} / 5 \mathrm{~mL}$ (a supplementary medicine) was low. For future studies, during the process of selecting surveyed medicines, these five medicines should be carefully considered by reason of their low availability.

In the private sector, the mean availability of cEMs in Phu Lý was the highest because this city is the centre of Hanam. All private drugstores in this city are NT drugstores. In other districts, most private drugstores are QT drugstores. Although both QT and NT drugstores are permitted to sell EMs, the availability of cEMs in NT drugstores (urban areas) was significantly higher than that in QT drugstores (rural areas). This can be a considerable issue for Hanam, especially in rural areas because a majority of private drugstores in this province are QT drugstores (90\%). In the countryside, numerous people are living below the breadline. The low availability in both sectors and high medicine prices in private drugstores can hinder their access to EMs.

By virtue of the endeavours of the Vietnamese government in reducing medicine prices through tender policies, the prices of cEMs in the public sector were reasonable. However, because of the low availability of cEMs in public health facilities, patients will have to purchase medicines in private drugstores. Sadly, the prices of almost all medicines in the latter were higher than those in the former and the mean availability of cEMs in private drugstores was also low. There are several possible reasons explaining the low availability of cEMs in Hanam. First, low demand and small profit margins can make manufacturers lack the motivation to produce cEMs. In addition, there are difficulties in manufacturing and storing child-friendly dosage forms, especially injections and suspensions. Although COVID-19 might not have been prevalent in Hanam, measures to contain this pandemic might have impacted access to medicines. For instance, the importation and distribution of medicines manufactured outside Vietnam would have been affected. In the public sector, cEMs can be excluded from procurement lists of hospitals due to high prices. Several other possible reasons include cEMs not locally produced, less effective tendering and procurement systems, inappropriate drug selection and insufficient knowledge on clinical standards.

\section{Strengths and limitations}

The reliable and standardised methodology developed by WHO/HAI was used for investigating cEMs in Hanam. IRPs of MSH were used to calculate the MPRs of medicines, allowing for international comparison among countries. However, at present, these reference prices are old (from the year 2015). In addition, the availability of medicines was calculated for the day of data collection, not for the whole month or year. Medicines' availability was reported as mean and SD (following WHO/HAI's instructions) although data were not normally distributed. Only 30 surveyed medicines cannot reflect the whole medicines for children on the market. This study was conducted in one province, and therefore the results may not be truly representative of Vietnam. A national survey should be conducted, and factors involving the low availability of cEMs should be comprehensively analysed.

\section{CONCLUSION}

In 2020, the mean availability of paediatric EMs was low, especially in rural areas in Hanam. Although medicine prices were high in private drugstores, most of them were affordable in both sectors. A national study on cEMs should be conducted soon. The results can assist the government to have further measures to enhance access to child-friendly formulations in the forthcoming years.

Acknowledgements The authors would like to thank Mr. Kha Quach Xuan, a leader of the Hanam Department of Health who assisted us in data collection. We also appreciate all the help of pharmacists working in health facilities selected for investigation in this research.

Contributors DXD: conceptualisation, methodology, software, formal analysis, investigation, data curation, visualisation, writing-original draft preparation, writingreview and editing. HTTN: conceptualisation, methodology, supervision, validation, writing-review and editing. VMN: conceptualisation, methodology, investigation, project administration, writing-review and editing.

Funding The authors have not declared a specific grant for this research from any funding agency in the public, commercial or not-for-profit sectors. 
Competing interests None declared.

Patient consent for publication Not required.

Ethics approval Researchers obtained approval to conduct this study from the ethical committee of Hanoi University of Pharmacy (reference number 10-20/ PCT-HĐĐÐ).

Provenance and peer review Not commissioned; externally peer reviewed.

Data availability statement Data are available on reasonable request. Please contact the corresponding author (dinhxuandai.224@gmail.com) if you are interested in accessing data from our research.

Supplemental material This content has been supplied by the author(s). It has not been vetted by BMJ Publishing Group Limited (BMJ) and may not have been peer-reviewed. Any opinions or recommendations discussed are solely those of the author(s) and are not endorsed by BMJ. BMJ disclaims all liability and responsibility arising from any reliance placed on the content. Where the content includes any translated material, BMJ does not warrant the accuracy and reliability of the translations (including but not limited to local regulations, clinical guidelines, terminology, drug names and drug dosages), and is not responsible for any error and/or omissions arising from translation and adaptation or otherwise.

Open access This is an open access article distributed in accordance with the Creative Commons Attribution Non Commercial (CC BY-NC 4.0) license, which permits others to distribute, remix, adapt, build upon this work non-commercially, and license their derivative works on different terms, provided the original work is properly cited, appropriate credit is given, any changes made indicated, and the use is non-commercial. See: http://creativecommons.org/licenses/by-nc/4.0/.

ORCID iD

Dai Xuan Dinh http://orcid.org/0000-0001-6387-2496

\section{REFERENCES}

1 World Health Organization. Children: improving survival and wellbeing, 2020. Available: https://www.who.int/en/news-room/factsheets/detail/children-reducing-mortality [Accessed 08 Jul 2021].

2 United Nations International Children's Emergency Fund (UNICEF). Children in Vietnam. Available: https://www.unicef.org/vietnam/ children-viet-nam [Accessed 08 Jul 2021].

3 United Nation Fund Population Agency (UNFPA) Vietnam. Results of the population and housing census, 2019. Available: https://vietnam. unfpa.org/en/news/results-population-and-housing-census-2019 [Accessed 08 Jul 2021]

4 World Health Organization. World health statistics 2020: monitoring health for the SDGs, sustainable development goals

5 World Health Organization. Signpost: WHO essential medicines. Available: https://www.who.int/rhem/signpost/essential_medicines/ en/ [Accessed 08 Jul 2021].

6 World Health Organization. Access to medicines: making market forces serve the poor. Geneva, Switzerland, 2017

7 World Health Organization. Better medicines for children project, overview of methods for medicines availability and pricing surveys, 2009

8 World Health Organization \& Health Action International. Measuring medicine prices, availability, affordability and price components. 2 nd edition, 2008

9 Balasubramaniam R, Benaragama BVSH, Sri Ranganathan S. A national survey of price and affordability of key essential medicines for children in Sri Lanka. Indian J Pediatr 2014;81:362-7.

10 Wang $X$, Fang Y, Yang S, et al. Access to paediatric essential medicines: a survey of prices, availability, affordability and price components in Shaanxi Province, China. PLoS One 2014;9:e90365.

11 Kazaryan I, Vardanyan L. Availability and affordability of medicines for children. J of Pharm Policy and Pract 2015:8:P10.

12 Swain TR, Rath B, Dehury S, et al. Pricing and availability of some essential child specific medicines in Odisha. Indian $\mathrm{J}$ Pharmacol 2015;47:496-501.

13 Sado E, Sufa A. Availability and affordability of essential medicines for children in the Western part of Ethiopia: implication for access. BMC Pediatr 2016;16:40.

14 Abrha S, Tadesse E, Atey TM, et al. Availability and affordability of priority life-saving medicines for under-five children in health facilities of Tigray region, Northern Ethiopia. BMC Pregnancy Childbirth 2018;18:464.

15 Dorj G, Sunderland B, Sanjjav T, et al. Availability, affordability and costs of pediatric medicines in Mongolia. BMC Pediatr 2018;18:149.
16 Sun X, Wei J, Yao Y, et al. Availability, prices and affordability of essential medicines for children: a cross-sectional survey in Jiangsu Province, China. BMJ Open 2018;8:e023646.

17 Orubu ESF, Robert FO, Samuel M, et al. Access to essential cardiovascular medicines for children: a pilot study of availability, price and affordability in Nigeria. Health Policy Plan 2019;34:iii20-6.

18 Hailu AD, Mohammed SA, Availability MSA. Availability, price, and affordability of who priority maternal and child health medicine in public health facilities of Dessie, north-east Ethiopia. BMC Med Inform Decis Mak 2020;20:221.

19 Bassoum O, Ba A, Tall AB, et al. Availability, management and use of priority Life-Saving medicines for Under-Five children in two health districts in Senegal: a cross-sectional study. Health 2020;12:204-18.

20 Tujo TM, Gurmu TG. Availability and utilization of who lifesaving medicines for children under five in public health facilities of the Jimma zone, South West Ethiopia: a cross-sectional survey. Int $J$ Pediatr 2020;2020:1-10.

21 Nguyen HTT, Dinh DX. Availability and price of some essential medicines used for children in Bacninh Province, 2014. Journal of Military Pharmaco-medicine 2015;8-TV:25-30 http://hocvienquany. edu.vn/Tapchi_YDHQS/Data/TapTinBaiVietPDF/TC\%20SO\%2082015\%20phan\%20I,\%20sua_04.pdf

22 General statistics office of Vietnam. number of health establishments. Available: https://www.gso.gov.vn/en/px-web/?pxid=E1102\& theme $=$ Health $\% 2 C \% 20$ Culture $\% 2 C \% 20$ Sport $\% 20$ and $\% 20$ Living $\%$ 20standard [Accessed 08 Jul 2021].

23 Vietnam Ministry of Health. The National essential medicine list, 2018. Available: http://vbpl.vn/boyte/Pages/vbpq-toanvan.aspx? ItemID=132228 [Accessed 08 Jul 2021].

24 World Health Organization. WHO Model List of Essential Medicines for Children, 7th list 2019.

25 World Health Organization. Priority life-saving medicines for women and children, 2012

26 Management Sciences for Health, World Health Organization. International medical products price guide, 2015

27 Health Action International. Collecting Evidence on Medicine Prices \& Availability - Health Action International. Available: http://haiweb. org/what-we-do/price-availability-affordability/collecting-evidenceon-medicine-prices-availability [Accessed 08 Jul 2021].

28 U. S. Bureau of Labor Statistics. CPI Inflation Calculator https://www. bls.gov/data/inflation_calculator.htm

29 The Vietnamese Government. Decree No. 90/2019/ND-CP on stipulating region-based minimum wages applied to employees working under labour contracts, 2019

30 British Medical Association, Royal Pharmaceutical Society of Great Britain, Royal College of Paediatrics and Child Health, Neonatal and Paediatric Pharmacists Group. BNF for children 2019-2020. Available: https://vnras.com/wp-content/uploads/2020/03/BNF-forChildren-BNFC-2019-2020-1.pdf [Accessed 08 Jul 2021].

31 Vietnam Ministry of Health, Agency of Health Examination and Treatment. Guidance on diagnosis and treatment for several common diseases of children, 2015. Available: https://kcb.vn/vanban/huongdan-chan-doan-va-dieu-tri-mot-so-benh-thuong-gap-o-tre-em [Accessed 08 Jul 2021]

32 Heidari E, Varmaghani M, Abdollahiasl A. Availability, pricing and affordability of selected medicines for noncommunicable diseases. East Mediterr Health J 2019;25:473-80.

33 Dong Z, Tao Q, Yan B, et al. Availability, prices and affordability of essential medicines in Zhejiang Province, China. PLoS One 2020;15:e0241761

34 Khuluza F, Haefele-Abah C. The availability, prices and affordability of essential medicines in Malawi: a cross-sectional study. PLoS One 2019;14:e0212125.

35 Nguyen NTT, Dien TM, Schindler C, et al. Childhood hospitalisation and related deaths in Hanoi, Vietnam: a tertiary hospital database analysis from 2007 to 2014. BMJ Open 2017;7:e015260.

36 United Nations International Children's Emergency Fund (UNICEF). Vietnam key demographic indicators. Available: https://data.unicef org/country/vnm/ [Accessed 08 Jul 2021].

37 Nguyen PTK, Tran HT, Fitzgerald DA, et al. Characterisation of children hospitalised with pneumonia in central Vietnam: a prospective study. Eur Respir J 2019;54:1802256.

38 Alefan Q, Amairi R, Tawalbeh S. Availability, prices and affordability of selected essential medicines in Jordan: a national survey. BMC Health Serv Res 2018;18:787.

39 Bizimana T, Kayumba PC, Heide L. Prices, availability and affordability of medicines in Rwanda. PLoS One 2020;15:e0236411.

40 World Health Organization. Child growth standards: Weight-forage. Available: https://www.who.int/tools/child-growth-standards/ standards/weight-for-age [Accessed 08 Jul 2021]. 